\section{Assessment Plan and Design: A Model for Enhancing Instruction in Economics Courses}

\section{Jill Caviglia-Harris and Brian Hill}

\section{Introduction}

The assessment of student outcomes in economics is recognised as an appropriate method for evaluating programme and teaching effectiveness. Such evaluations have been mandated by accrediting agencies of colleges and universities, university systems and specific degree programmes to ensure maintenance of instructors, curricula and institutions. Since 1998, the US Department of Education has required that accrediting agencies include assessment components in their provisions. In response to this requirement, the most commonly used measurements of outcomes assessment include job placement rates, scores on certified exams, employment rates and performance on exams in the major field (McCoy et al., 1994). Although together these data can provide a good picture of programme quality and student achievement, most of these measures do not provide insight into the most important aspect of outcomes assessment: the ability to implement continuous improvement in instruction and to improve course and programme design.

One of the more difficult and time consuming components of course and programme assessment is closing this gap in the 'assessment loop'. For several valid reasons, such as changes in staff, lack of rewards, and the lack of an efficient and consistent approach, assessment is often initiated in a piecemeal fashion. To this end, this paper develops a systematic approach to course assessment. We highlight seven distinct steps and explain these procedures with an assessment tool that was developed for an economics foundation course. Our goal is to present an approach that could be used in various settings. We begin with developing goals for the course and align these with course topics. We develop an assessment tool that is geared towards these goals and then use data collected over a seven year-time frame first to improve the instrument and later to guide improvements for course instruction. We find that using a tool that is specifically designed to meet the needs of students and instructors in the programme is more valuable than one designed at the national level. This paper addresses Walstad's (2001) call (and Johnston et al.'s 2001 reiteration) for more research in the area of assessment and the development of new standardised tests as alternatives to the Test of Understanding in College Economics (TUCE) to measure learning outcomes. While there are significant costs involved in the development of a course specific assessment tool, benefits include the evaluation of questions and data that are closely tied to the curriculum and learning goals of the department.

\section{Outcomes assessment in economics}

Outcomes assessment tools can be divided into two broad categories: 1 ) the evaluation of students on exams that cover material from the programme or course to be evaluated; and 2) the collection of data from independent sources including graduation rates, employer satisfaction and employment rates. The first category of tools (Type 1) provides in-depth information that can be used to make improvements to specific courses or programmes. For example, if students are found to be weak in a particular topic as identified from exam results, instructors can devote more time to the topic in future classes. The second category of tools (Type 2) is important in identifying strengths and weaknesses in a programme; however the best methods for improvement are not apparent from a review of these data. For example, if the graduation rates of economics majors are relatively low this does not provide information on the causes of this lower rate and any indication of how the programme can be improved (or if it should be improved) to address the concern.

The 'Type 1' assessment tools can be further divided between summative and formative assessment. Summative assessment refers to the use of graded evaluation of understanding through exams, presentations and/or projects to determine mastery of subject matter, while formative assessment refers to the use of graded evaluation to identify learning problems and guide instruction (Walstad, 2005). Currently one of the most widely used Type 1 tools used to evaluate student performance in Principles of Economics courses administered in the US is the Test of Understanding in College Economics (TUCE) first established in the 1960s. The exam was designed to evaluate specific content areas in microeconomic and macroeconomics principles and performance on three types of questions: 1) recognition and understanding, 2) simple application, and 3) complex application (Saunders and Welsh, 1975). Although widely recognised as an adequate measure 
of economic knowledge and used in many studies of student achievement (Rothman and Scott, 1973; Kennedy and Siegfried, 1997; Saunders and Saunders, 1999; Finegan and Siegfried, 1999), several shortcomings have also been noted (Swartz et al., 1980; O'Neill 2001).

The assessment tool developed as part of this study falls within the Type 1 category, as it includes questions on common core materials and learning goals agreed on by departmental faculty. The method better suits the objectives of this paper as it permits the development of targeted modifications to teaching approaches and learning tools that are tailored to outlined goals. Such an approach may be particularly useful for departmental assessment, and the shared lessons enlightening for new faculty as they design courses for a student body they may not be familiar with (Webber, 2005)

\section{Assessment plan: evaluation of student learning goals and development of tool}

The first step in the assessment process presented here is the development of an appropriate course of action. Using the backward course design method, faculty first defined course goals (Table 1), placing importance on the information and theories that students were expected to retain and apply two to three years after the completion of the course (see Fink, 2003). With guidance from the proficiencies approach to teaching (Hansen, 2001) we focused on the first three proficiencies appropriate for introductory classes including the ability to: i) access existing knowledge; ii) display command of existing knowledge; and iii) interpret existing knowledge. We identified the following five goals as fundamental to an introductory course in microeconomics:

1. Students should understand the allocation of scarce resources, that individuals face tradeoffs, the meaning of opportunity cost, and how to use marginal reasoning when making decisions.

2. Students should understand how supply and demand together set the price of a good and the quantity sold and the role of prices in allocating scarce resources.

3. Students should understand the concept of elasticity.

4. Students should understand how to calculate and evaluate economic profits.

5. Students should understand the characteristics of different market structures, how firms within these market structures decide how much output to produce, and their long-term exiting and entering strategies.

Three to seven multiple-choice questions were developed for each learning goal. These questions were evaluated for content, design and wording; and to verify the
Table 1: Topics and course goals for principles of microeconomics

\begin{tabular}{|c|c|c|c|c|}
\hline Topic & Learning Objectives Addressed & $\begin{array}{l}\text { 3efore the } \\
\text { Exam } \\
\text { Revision } \\
\text { (Per cent } \\
\text { Correct) } \\
\mathrm{n}=429\end{array}$ & $\begin{array}{l}\text { After the } \\
\text { Exam } \\
\text { Revision } \\
\text { (Per cent } \\
\text { Correct) } \\
n=346\end{array}$ & $\begin{array}{l}\text { After the } \\
\text { Teaching } \\
\text { Approach } \\
\text { Change } \\
\text { (Per cent } \\
\text { Correct) } \\
\mathrm{n}=410\end{array}$ \\
\hline $\begin{array}{l}\text { Decision } \\
\text { Making }\end{array}$ & $\begin{array}{l}\text { Understand that economics is about } \\
\text { the allocation of scarce resources, that } \\
\text { individuals face tradeoffs, the meaning } \\
\text { of opportunity cost, how to use marginal } \\
\text { reasoning when making decisions, how } \\
\text { incentives affect people's behaviour, why } \\
\text { trade among people or nations can be goo } \\
\text { for everyone, and why markets are a good, } \\
\text { but not perfect, way to allocate resources. }\end{array}$ & 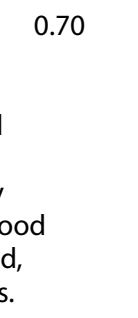 & 0.78 & 0.80 \\
\hline $\begin{array}{l}\text { Demand } \\
\text { and } \\
\text { Supply }\end{array}$ & $\begin{array}{l}\text { Understand the determinants of demand } \\
\text { and supply for a good in a competitive } \\
\text { market, how supply and demand } \\
\text { determine equilibrium price and quantity, } \\
\text { and the role of prices in allocating scarce } \\
\text { resources in market economies. }\end{array}$ & $\begin{array}{l}0.69 \\
y_{1}\end{array}$ & 0.65 & 0.70 \\
\hline Elasticity & $\begin{array}{l}\text { Understand the meaning of the } \\
\text { elasticity of demand and supply, what } \\
\text { determines the elasticity of demand and } \\
\text { supply, and the concept of elasticity in } \\
\text { different markets. }\end{array}$ & 0.68 & 0.63 & 0.66 \\
\hline $\begin{array}{l}\text { Profit } \\
\text { Maximisation }\end{array}$ & $\begin{array}{l}\text { Understand what items are included in } \\
\text { a firm's costs of production, the link } \\
\text { between a firm's production process } \\
\text { and its total costs, the meaning of } \\
\text { average total cost and marginal cost and } \\
\text { how they are related, the shape of a typical } \\
\text { firm's cost curves, how economics profits } \\
\text { are calculated, and how firms decide how } \\
\text { much output to produce. }\end{array}$ & 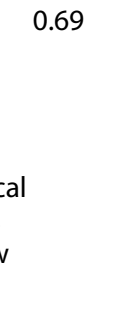 & 0.59 & 0.62 \\
\hline $\begin{array}{l}\text { Market } \\
\text { Structure/ } \\
\text { Industrial } \\
\text { Organisation }\end{array}$ & $\begin{array}{l}\text { Understand what characteristics make a } \\
\text { market competitive, how monopoly } \\
\text { power is derived, how competitive and } \\
\text { monopoly firms decide how much output } \\
\text { to produce, how firms decide when to } \\
\text { shut down production temporarily, how } \\
\text { competitive firms decide whether to exit } \\
\text { or enter a market, and how firm behaviour } \\
\text { determines a market's short-run and } \\
\text { long-run supply curves. }\end{array}$ & 0.61 & 0.44 & 0.55 \\
\hline
\end{tabular}


Table 2: Description of exam questions by level of difficulty

\begin{tabular}{lccc}
\hline Level of Difficulty & $\begin{array}{c}\text { Per cent of Questions } \\
\text { on Original Set of 25 } \\
\text { Exam Questions }\end{array}$ & $\begin{array}{c}\text { Per cent of Questions } \\
\text { on Revised Set of 25 } \\
\text { Exam Questions }\end{array}$ & $\begin{array}{c}\text { Per cent } \\
\text { Correct } \\
\text { (Both Exams) }\end{array}$ \\
\hline Level 1 & 0.24 & 0.20 & 0.73 \\
Level 2 & 0.40 & 0.48 & 0.65 \\
Level 3 & 0.36 & 0.32 & 0.59 \\
Average Difficulty (All Levels) & 2.12 & 2.12 & 0.66 \\
\hline
\end{tabular}

Note: Questions determined to be poor discriminators of student achievement and/or had a relatively high or low level of correct responses were edited for content. Replacement questions were designed to better discriminate and covered the same topic as the original question.

material was appropriately matched to course objectives. The questions were equally divided between material covered in the early and later part of the semester and the difficulty categories classified under Bloom's (1956) cognitive taxonomy using the hierarchy of 1 ) recall, 2) evaluate (calculate), and 3) create (apply analytical thought) (Table 2). Because these questions are consistent across both professors and time, they provide faculty with robust information concerning the performance of students.

Twenty five common multiple-choice questions were chosen from the above to evaluate student achievement and assess the course of interest through yearly evaluation at Salisbury University, a regionally accredited, four-year comprehensive state university located on the Eastern Shore of Maryland.1 Questions developed for the assessment tool serve multiple ends in maintaining a position of continual improvement. The core questions are directed at content that faculty consider essential to any introductory microeconomics course, and thus serve to offer a minimal outline for the courses, providing students an opportunity to acquire a common set of skills regardless of the course section or semester of enrollment. ${ }^{2}$ We call these 'core' questions or 'common questions' because these were included on the final exams of all instructors of the course beginning in the Fall 2001 semester, but were only one component of all exams for which they were included.

\section{Evaluation and modification of the assessment Tool}

After developing the tool, our next step included the examination of the assessment tool (i.e. the 25 common questions) to determine rigour, applicability and quality. Data on student performance on the chosen assessment tool were collected for five semesters before an evaluation of question quality was made (once the Spring 2004 semester concluded). In this evaluation, 11 'poor' questions were identified using the index of discrimination and the percentage of correct responses as the criteria. We defined poor questions as those with an index of discrimination below 0.30 (Saunders and Welsh, 1975; Swartz et al.,1980) or a percentage correct of above 90 per cent or below 10 per cent (Table 3). ${ }^{3}$ Replacement questions were designed with full departmental review to better serve as discriminators. Interestingly, we found that questions on demand and supply analysis, most of which fell under the application category of difficulty, to be the best discriminators while topics covered later in the semester (such as applications of perfect competition and monopoly behaviour) to be weaker discriminators. In addition, we found farming examples

Table 3: Per cent correct, discrimination index and topic

\begin{tabular}{|c|c|c|c|c|c|c|c|}
\hline Question & $\begin{array}{l}\text { Difficulty } \\
\text { Level }\end{array}$ & Obs & $\begin{array}{c}\% \\
\text { Correct }\end{array}$ & $\begin{array}{c}\text { Bottom } \\
25 \% \\
\text { Correct }\end{array}$ & $\begin{array}{c}\text { Top } \\
25 \% \\
\text { Correct }\end{array}$ & $\begin{array}{l}\text { Discrim- } \\
\text { ination } \\
\text { Index }\end{array}$ & Topic \\
\hline $1 \mathrm{a}$ & 1 & 429 & 0.93 & 0.85 & 0.98 & 0.13 & Decision Making \\
\hline $1 \mathrm{~b}$ & 1 & 756 & 0.94 & 0.90 & 0.99 & 0.09 & Decision Making \\
\hline $2 a$ & 1 & 429 & 0.48 & 0.37 & 0.54 & 0.17 & Decision Making \\
\hline $2 \mathrm{~b}$ & 3 & $\begin{array}{l}756 \\
118\end{array}$ & 0.81 & 0.62 & 0.96 & 0.34 & Decision Making \\
\hline 3 & 1 & $\begin{array}{c}5 \\
118\end{array}$ & 0.65 & 0.47 & 0.82 & 0.34 & Decision Making \\
\hline 4 & 2 & 5 & 0.74 & 0.51 & 0.93 & 0.42 & Demand and Supply \\
\hline $5 a$ & 2 & 429 & 0.56 & 0.45 & 0.68 & 0.23 & Market Structure \\
\hline $5 b$ & 2 & $\begin{array}{l}756 \\
118\end{array}$ & 0.75 & 0.67 & 0.80 & 0.12 & Market Structure \\
\hline 6 & 3 & $\begin{array}{c}5 \\
118\end{array}$ & 0.67 & 0.43 & 0.87 & 0.44 & Demand and Supply \\
\hline 7 & 3 & 5 & 0.64 & 0.43 & 0.83 & 0.40 & Demand and Supply \\
\hline $8 a$ & 3 & 429 & 0.64 & 0.51 & 0.76 & 0.25 & Demand and Supply \\
\hline $8 b$ & 3 & $\begin{array}{l}756 \\
118\end{array}$ & 0.79 & 0.77 & 0.84 & 0.07 & Demand and Supply \\
\hline 9 & 2 & $\begin{array}{c}5 \\
118\end{array}$ & 0.61 & 0.32 & 0.87 & 0.54 & Elasticity \\
\hline 10 & 2 & 5 & 0.74 & 0.59 & 0.87 & 0.28 & Elasticity \\
\hline $11 a$ & 3 & 429 & 0.50 & 0.32 & 0.70 & 0.38 & Elasticity \\
\hline
\end{tabular}


Table 3: (continued) Per cent correct, discrimination index and topic

\begin{tabular}{|c|c|c|c|c|c|c|c|}
\hline Question & $\begin{array}{c}\text { Difficulty } \\
\text { Level }\end{array}$ & Obs & $\begin{array}{c}\% \\
\text { Correct }\end{array}$ & $\begin{array}{c}\text { Bottom } \\
25 \% \\
\text { Correct }\end{array}$ & $\begin{array}{c}\text { Top } \\
25 \% \\
\text { Correct }\end{array}$ & $\begin{array}{l}\text { Discrim- } \\
\text { ination } \\
\text { Index }\end{array}$ & Topic \\
\hline $11 \mathrm{~b}$ & 3 & $\begin{array}{l}756 \\
118\end{array}$ & 0.38 & 0.24 & 0.60 & 0.36 & Elasticity \\
\hline 12 & 2 & $\begin{array}{c}5 \\
118\end{array}$ & 0.85 & 0.70 & 0.95 & 0.25 & Elasticity \\
\hline 13 & 3 & 5 & 0.54 & 0.39 & 0.72 & 0.33 & Demand and Supply \\
\hline $14 a$ & 2 & 429 & 0.89 & 0.74 & 0.95 & 0.21 & Demand and Supply \\
\hline $14 b$ & 2 & 756 & 0.69 & 0.58 & 0.83 & 0.26 & Demand and Supply \\
\hline $15 a$ & 3 & 429 & 0.61 & 0.42 & 0.74 & 0.32 & Demand and Supply \\
\hline $15 b$ & 1 & $\begin{array}{l}756 \\
118\end{array}$ & 0.72 & 0.54 & 0.88 & 0.34 & Demand and Supply \\
\hline 16 & 3 & $\begin{array}{c}5 \\
118\end{array}$ & 0.68 & 0.49 & 0.85 & 0.35 & Demand and Supply \\
\hline 17 & 1 & $\begin{array}{c}5 \\
118\end{array}$ & 0.72 & 0.51 & 0.88 & 0.36 & Profit Maximisation \\
\hline 18 & 1 & $\begin{array}{c}5 \\
118\end{array}$ & 0.72 & 0.55 & 0.86 & 0.32 & Profit Maximisation \\
\hline 19 & 2 & 5 & 0.56 & 0.25 & 0.86 & 0.61 & Profit Maximisation \\
\hline $20 a$ & 2 & 429 & 0.39 & 0.21 & 0.57 & 0.36 & Profit Maximisation \\
\hline $20 b$ & 2 & 756 & 0.48 & 0.41 & 0.58 & 0.17 & Profit Maximisation \\
\hline $21 a$ & 2 & 429 & 0.91 & 0.81 & 0.98 & 0.17 & Profit Maximisation \\
\hline $21 \mathrm{~b}$ & 2 & $\begin{array}{l}756 \\
118\end{array}$ & 0.73 & 0.53 & 0.92 & 0.38 & Profit Maximisation \\
\hline 22 & 3 & $\begin{array}{c}5 \\
118\end{array}$ & 0.61 & 0.42 & 0.80 & 0.39 & Profit Maximisation \\
\hline 23 & 2 & 5 & 0.49 & 0.25 & 0.75 & 0.49 & Market Structure \\
\hline $24 a$ & 3 & 429 & 0.60 & 0.52 & 0.69 & 0.17 & Market Structure \\
\hline $24 b$ & 2 & 756 & 0.37 & 0.22 & 0.62 & 0.39 & Market Structure \\
\hline $25 a$ & 1 & 429 & 0.82 & 0.72 & 0.91 & 0.19 & Market Structure \\
\hline $25 b$ & 2 & 756 & 0.50 & 0.36 & 0.72 & 0.37 & Market Structure \\
\hline Average & & & 0.66 & 0.50 & 0.81 & 0.31 & \\
\hline
\end{tabular}

(often used in applications of perfect competition) to be confusing to students and replaced all references to agriculture. The questions changed by level in some cases, but the average exam difficulty level did not change between the exam formats nor did the question topics (Table 2). The revised exam was designed to include fewer questions requiring recall and more that require calculations, logic and applications of economic theory.
Detail on the revised questions, first administered in the Fall 2004 semester, are reported in Table 3 with an ' $a$ ' and ' $b$ ' after each number indicating the question responses before and after the exam revision, respectively. The revised question responses either exhibited improvements in the discrimination index or the per cent correct predictions. Students continued to perform more poorly on the topics introduced later in the semester after the revision, although the newer questions within this category were clearly better discriminators and overall performance improved. Even so, several questions could still be identified as poor discriminators while additional questions included relatively few correct responses. Instead of further revising the instrument, the opportunity was used to analyse student responses in relation to course rigour, topics covered and teaching approaches to determine if improvements could be made to instruction to better reach these learning goals.

\section{Evaluation of student learning and course instruction}

Data used throughout the assessment process include 1185 observations from students enrolled in microeconomics principles courses taught over 13 semesters by five different instructors between 2001 and 2007. These data include student characteristics composed from university records and performance on the assessment tool.Student characteristics include major, year, gender, ethnicity, grade point average (GPA) prior to taking microeconomics principles, verbal and math scores on the SAT (Standardised Achievement Test used for US college admissions; the combined math and verbal score ranges from 400-1600), cumulative credit hours, and the number of withdrawn courses prior to taking microeconomics principles. As seen in Table 4, the

Table 4: Descriptive statistics for student data

\begin{tabular}{|c|c|c|c|c|c|}
\hline & Mean & Std. Dev. & Minimum & Maximum & Obs. \\
\hline SAT score & 1092.25 & 121.86 & 540 & 1490 & 951 \\
\hline GPA prior to taking the course & 2.47 & 1.07 & 0 & 4 & 1185 \\
\hline $\begin{array}{l}\text { Number of courses withdrawn from } \\
\text { before taking the course }\end{array}$ & 0.57 & 0.96 & 0 & 7 & 1185 \\
\hline $\begin{array}{l}\text { Transfer Status; } 1 \text { for transfer } \\
\text { students; } 0 \text { otherwise }\end{array}$ & 0.30 & 0.46 & 0 & 1 & 1185 \\
\hline $\begin{array}{l}\text { College Course Hours taken } \\
\text { Prior to the Course }\end{array}$ & 39.25 & 23.70 & 0 & 129 & 1185 \\
\hline $\begin{array}{l}\text { Gender of student }= \\
1 \text { for females; } 0 \text { otherwise }\end{array}$ & 0.38 & 0.49 & 0 & 1 & 1185 \\
\hline $\begin{array}{l}\text { Minority status }=1 \text { is minority; } \\
0 \text { otherwise }\end{array}$ & 0.10 & 0.30 & 0 & 1 & 1185 \\
\hline
\end{tabular}


average student enrolled in microeconomics principles had an average SAT score of 1092 , an average GPA (prior to taking the course) of 2.47 , completed 39 credit hours, and withdrew from approximately 0.6 classes. These combined courses were 38 per cent women and 10 per cent minority ethnic.

Data used in the analysis are divided between the two exam formats: the first used in the department from 2001-2004 and the second (with 11 re-worded questions) administered between 2004 and 2007. The complete student sample of 951 students (with reported SAT scores) can be divided between the 422 that took the first version of the assessment tool, and the 529 to take the revised exam. ${ }^{4}$ Returning to Table 2, students performed best on those questions pre-determined to be of lowest difficulty and worst on those of the highest difficulty both before and after the exam revisions, hence verifying our classification scheme. Also returning to Table 1 , questions are divided by topic and matched with course learning goals. These topics are presented in chronological order (as presented in the typical course). Note that student performance by topic declines according to this order before and after the exam revisions, as well as for the exams taken after the course instructional changes (to be described in the next section). Students therefore have more difficulty with topics covered later in the semester either due to the increased difficulty or because of the cumulative nature of the course. ${ }^{5}$

Finally, Table 3 presents the performance of students by question, the difficulty level, the discrimination index, and question topic. Correct responses range from 32 to 95 per cent. While the quality of the question may be partially determined by the index of discrimination, the per cent of correct responses can assist in determining where to focus future teaching efforts. Those questions with relatively low correct responses (between 32 and 70 per cent) are mainly from topics 2-5 (all but those on decision making) and are more often from the level of difficulty of 2 and 3 .

Several approaches are used to guide course instructional changes. First, we estimate the quality of the assessment tool on a per question basis and estimate student performance to identify student weaknesses. Next, we use these identified weaknesses in both student performance and course instruction to make changes to teaching practices. These changes are evaluated with an estimation of student performance to test for significant differences in student scores before and after the instructional changes.

\section{Estimations of student achievement to inform Course instruction change}

Our empirical approach includes estimates of student performance at two different points in the analysis. After collecting data through Fall 2006, we first estimated performance to determine student weaknesses and identify methods for improving both teaching and learning. In the interest of space, these results are not provided in the paper (but are available upon request). Instead, conclusions from the analysis are reported to shed light on the instructional changes made. After the changes were made, we collected data for another three semesters and estimated student performance to determine any effectiveness. We report both the empirical results and our conclusions from this empirical analysis in the following section.

We begin with a brief discussion of our regression analysis conducted after the Fall 2006 semester. This regression analysis was conducted on each question and was used to provide pointed policy recommendations for programme assessment. For example, if performance on a question is not largely determined by previous student knowledge (i.e. SAT score) or previous achievement (prior GPA) this would suggest that the question may be poorly written or that faculty have not addressed the question in a sufficient manner. Well-written questions that do not discriminate well between good and poor students and are largely undetermined by student prior knowledge and skill (according to the regression results) are likely to be the best indicators of weakness of coverage in the classroom. Other questions with variations in discriminatory power and predictability by student characteristics warrant further consideration. Select results are discussed for questions of interest, including those questions with poor performance and/or discriminatory power.

Students performed poorest on revised questions 24 (37 per cent correct) and 11 (35 per cent correct), the first covering content within the market structure topic and the second on elasticity. These questions are of varying level - the first is level 3 and the second is level 2. Both require students to recall economic theory. SAT is significant for both questions at varying significance levels (at the 10 per cent level for question 24,5 per cent for question 11). However other motivational factors such as the number of withdrawn courses and prior GPA are not significant for either question. Finally, instructor effects appear to be strong for question 24, suggesting that there may be differences in the level of coverage by faculty members. Both questions cover material that is routine for a principles course: equating marginal revenue and marginal costs leads to profit maximisation for firms in all markets (not in one market structure or another) and the relationship between revenue and the elasticity of demand. These topics were identified for programme review. Students also performed poorly on questions 20 (interpreting marginal product from a graph of total product) and question 23 (entry and exit in a competitive market). Question 20 is also predicted poorly (66 per cent of the observations are predicted correctly by the stated coefficients). Furthermore question 20 does not include any significant motivational factors. Instructor effects are the only highly significant predictors.

Additional questions of concern (in increasing order of correct response) include: revised question 25 (monopolies are constrained by demand not marginal cost, 
social agenda, etc.), question 13 (the results of an effective or binding price ceiling), question 19 (identifying when a firm will shut down in the short run) and question 9 (solving and interpreting the elasticity of demand). Results for these questions suggest that the concepts of a binding price ceiling, calculation and interpretation of the elasticity of demand and shut down decisions of the firm are better understood by students who have performed well in other courses, while the marginal product (as derived from total product) and entry and exit in competitive markets are equally misunderstand by all students.

\section{Determination and implementation of course instruction change}

Our findings from the above analysis were next used to guide the direction of our future teaching efforts. A first step in the design of suggestions for instructional change was the identification of questions that were both poor discriminators (Table 3 ) and not predicted well by student prior skill and knowledge (results available upon request). A second category of questions that provided suggestions to the faculty include those predicted well by prior student knowledge. If answering a question correctly is the result of being a 'good' student then faculty may need to focus their attention towards the less motivated students when addressing these concepts. Finally, the strengths of students and course instruction were identified with our third set of criteria including questions with a relatively high percentage correct and predicted well by prior student knowledge. One topic included in this category is an understanding of demand and supply interaction. The questions related to this topic (on all levels) were answered correctly at relatively high percentages or were well predicted by prior student knowledge. For the same reasons another topical strength identified was profit maximisation.

Several general suggestions were made to faculty regarding improvements in teaching strategy. First, it was suggested that faculty spend more time on the topics introduced later in the semester. Students were found to have a much better grasp of material presented earlier, specifically questions on demand and supply interaction at all levels were well understood by students of all levels. It was therefore suggested that faculty continue to use and review this material throughout the semester - but within the content of the more advanced (or more final) topics. In addition, students appeared to struggle with the concepts of elasticity and are unable to recall them later in the semester. It was therefore suggested that faculty review these concepts prior to the final exam. Finally, since students have more difficulty with questions that require the application of economic theory, we suggested that faculty use more rigorous questions within their lectures, exams and/or homework assignments and to increase the number of required practice questions.
In addition to these suggestions, a one-page supplement was prepared for students including the common course topics, learning objectives, methods of study suggestions by topic, and suggested review questions from the text (Appendix A).This supplement is not intended as a review sheet for the microeconomics principles courses for two reasons. First, the sheet does not include all of the topics covered in the individual sections of the course taught, but rather the core topics covered in each course and tested with the 25 common questions. In addition, the table serves to supplement and assist with studying techniques rather than serve as a review of material. We were careful not to include information that was geared to any specific questions included in the assessment but rather provide strategies for the broad topics linked to learning objectives. For example study tips suggested for demand and supply analysis include the use of practice questions found at the end of chapters, the checking of answers, and quizzing of fellow students. Appropriate studying techniques include graphing to determine what occurs to the equilibrium price and quantity when demand and/or supply change; to identify shortages and surpluses in a graph; and the use of graphs to address policy questions (see Appendix A for further details).

In sum, programme changes adopted by all the course instructors in the Spring 2007 semester included 1) the reorganisation of course topics (early topics were allocated less time while the later topics to build on (and review) these concepts were allotted more time), 2) a review of difficult concepts identified prior to the final exam, 3) the development of additional practice questions (assigned in or out of class) and 4) the distribution of a course supplement (including the course objectives). While these changes were relatively simple in many respects, they made significant changes to the course for most faculty. Actually, without previous analysis of student performance faculty would not have been aware of any possible benefits of these actions nor would they have been developed or adopted. In reality, faculty were surprised by some of the results. For example, while students appear to struggle throughout the course with the differentiation between the concepts of demand and quantity demanded (and the same differentiation for supply), results suggested that by the end of the semester any remaining difficulties were due to student prior knowledge or skill differences rather than course coverage.

\section{Analysis of and changes to course instruction}

Data collected for the revised assessment instrument both before and after the instructional changes (noted in the previous section) are used to investigate any impacts of these course modifications on student learning. We estimate overall exam score first using OLS and a Heckman selection model to account for a large number of missing observations for the SAT score (Grove et al., 2006); and continue 
with the estimation results for specific questions of interest. We present the results for the OLS model only, as the Heckman selection model does not indicate any significant bias resulting from our missing data. ${ }^{6} \mathrm{As}$ a disclaimer, it is of course possible that any positive changes in question performance could be attributed to faculty 'teaching to the exam'. We developed a policy such that this would not occur, although it is still possible that this occurred subconsciously. In addition, it is also possible that instructors changed their courses in different ways and at different times throughout the process. Given the short time frame of the post-instructional change (i.e. three semesters) we assume that any changes instituted are reflected by, and can be attributed to, our assessment process.

In more detail, estimations of student achievement are made using the standard reduced form production function (Raimondo et al., 1990; Bonesronning, 2003):

$A_{i t}=\alpha_{0}+\beta_{1} A_{i t-1}+\beta_{2} S_{i t}+\beta_{3} l_{t}+\beta_{3} M_{t}+e_{i t}$

where the dependent variable, $A_{i t}$ is achievement on the exam (or question) for student $i$ at time $t$, and is dependent on achievement in the previous semester, $A_{i t-1}$ a vector of student characteristics, $S_{i t}$, class instructor, $I_{t}$, student motivation and skill $M_{t}$, and a random error term, $e_{i t} . A_{t-1}$ is represented by the GPA recorded one semester prior to taking the course. Student characteristics (C) include age, minority status, transfer status and gender. A dummy term (I) is used to control for differences between course instructors. And finally prior GPA, number of courses withdrawn from before taking the course and combined SAT scores ${ }^{7}$ represent student motivation and skill (M). Additional value added of the course could be measured with pre-course and post-course tests of ability. Due to the inconsistent manner in which such methods were employed by faculty teaching the course, such data are not available in this analysis, but are recommend for future study.

We begin by estimating overall score on the instrument ${ }^{8}$ with factors that instructors cannot fully address with teaching strategies such as prior knowledge and skill (i.e. SAT scores and prior GPA) and motivation at the university (i.e. number of withdrawn courses) and find these indicators (in addition to the indicator for instructional change) to explain approximately 28 per cent of the overall score, while the addition of student and instructor characteristics explains only 1 additional per cent of the score (Table 5). In addition, students are found to perform significantly better on the exam after the programme changes were made. Students correctly answered nearly one more question out of 25 after the programme changes were implemented. Similarly, the percentage of correct responses are found to increase for each topic covered (Table 1).
Table 5: Estimations of Student Performance (Pre and Post Teaching Approach Change)

Exam Score

Exam Score (Motivation and Skill)

Constant

SAT score (divided by 10)

0.12

$0.78^{* * * *}$

(0.14)

GPA prior to taking the course

$-0.26^{* * *}$

Number of courses withdrawn from before

$0.12^{* * *}$

taking the course

$1.22^{* *}$

Transfer Status; 1 for transfer students; 0 otherwise

$-0.32^{* *}$

$(0.26)$

(0.15)

$0.99 * *$

College Course Hours taken Prior to the Course

Gender of student $=1$ for females; 0 otherwise

Minority status $=1$ is minority; 0 otherwise

Instructor $1=1$ if instructor $1 ; 0$ otherwise

Instructor2 $=1$ if instructor $2 ; 0$ otherwise

Instructor $3=1$ if instructor $3 ; 0$ otherwise

Approach Change $=1$ if the questions were $1.22^{* * *}$ $0.90^{* * *}$ answered after the teaching approach change

was made; 0 otherwise

\begin{tabular}{lll}
\hline $\mathrm{N}^{*}$ & 592 & 592 \\
$\mathrm{R}$-squared & 0.28 & 0.29 \\
Adj-R-squared & 0.28 & 0.29 \\
\hline
\end{tabular}

Notes: Coefficients reported, standard errors indicated in parenthesis; ${ }^{* * *},{ }^{* * *}$ indicate significance at the 10,5 and 1 per cent levels, respectively

*Observations include students to take the revised exam pre-and post instructiona change. 
Table 6 presents the results of the estimation of selected questions of interest including those that were the focus of programme change and those that showed significant change.Overal, results indicate that the programme changes either had a positive and significant impact on performance by question or had no impact at all.Questions 5,23 and 25 each tested material covered at the end of the semester on market structure. After the programme changes, these topics were covered in more detail resulting in improved student performance.In addition, performance on questions about demand and supply interaction showed mixed results after the programme changes, with improvement on one (question 13) but no change in

performance on the other (question 6). Finally, performance on questions on elasticity ( 9 and

11) showed no significant improvement after the programme change.

\section{Conclusions}

The assessment of university programmes and courses has become of increasing importance in the accreditation of schools, departments and curricula. More importantly the process can lead to changes that improve teaching and learning. If done efficiently the development of an assessment process need not be an overwhelming task. To this end, the paper presents an assessment plan through example that may be implemented for a variety of courses within any university programme. These steps are outlined as follows:

1. Develop the Assessment Plan

a. Evaluate learning goals for the course or programme

b. Identify topics that relate to each of the learning goals

c. Determine minimum number of required topics to be covered in the course

2. Develop the Assessment Tool

a. Determine the appropriate method for assessment (i.e. format and question type)

b. Develop questions related to each of the identified learning goals of the course

c. Determine adequate coverage of question in terms of topic and rigour

d. Revise with full input from course instructors

e. Design a pre-and post course test to evaluate student learning independent of the assessment plan

3. Evaluate the Assessment Tool

a. Compare results across multiple sections and years

b. Method of comparison will depend on assessment tool chosen

c. Discrimination indices can be used for multiple choice and essay questions

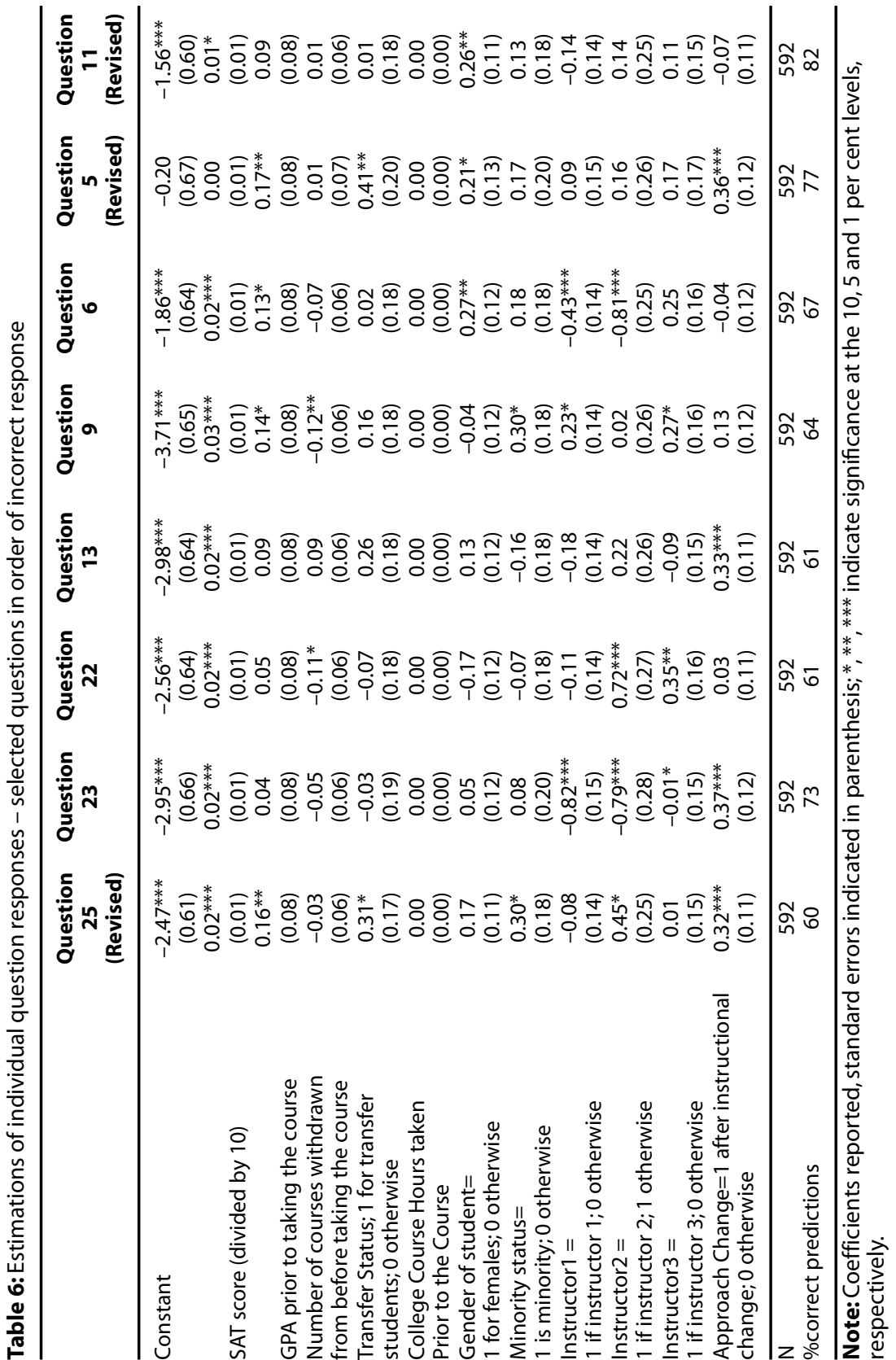


4. Evaluate Student Learning and Course Instruction

a. Identify student weaknesses and strengths through statistical testing

b. Evaluate course coverage of identified student weaknesses and strengths in terms of rigour and topic

5. Initiate Changes to Course Instruction

a. Discuss results of the student evaluation and course coverage comparison with instructors

b. Determine approaches to be implemented to make improvements in student understanding and performance

6. Evaluate Student Performance

a. Identify student weaknesses and strengths through statistical testing

b. Evaluate course coverage of identified student weaknesses and strengths in terms of rigour and topic

c. Identify changes in student weaknesses and strengths

7. Continuous Improvement

a. Requires revisiting steps 1-7

As part of the assessment presented in this paper and following the steps above, 25 common multiple-choice questions were developed to evaluate student achievement and assess an economics course through yearly evaluation. Student data were used to revise the assessment tool and later to evaluate the programme and student performance. The analysis of student data by topic, question and leve of difficulty enabled faculty to gain a better understanding of student weaknesses and address these in the classroom through the adoption of a variety of different teaching approaches.

The single most beneficial aspect of the development and analysis of the assessment tool was the ability to identify programme weaknesses and strengths. While it may be possible to analyse student performance from exams alone, faculty gained a much more comprehensive understanding of student learning (and any lack of) through this analysis. Furthermore, we were surprised by some of the results. The process of designing and discussing programme changes enabled faculty to re-evaluate course topics, teaching methods and student learning. With full faculty input, the process strengthened both this foundation course and individual lectures and resulted in a positive impact on performance, as students were found to perform better on targeted topics as well as the exam overall. We attribute these improvements to the introduction of more rigorous examples and assignments, the introduction of targeted lecture topics, and the highlighting of course learning goals to students. Although not complicated programme revisions, these simple changes appear to have made a significant impact.

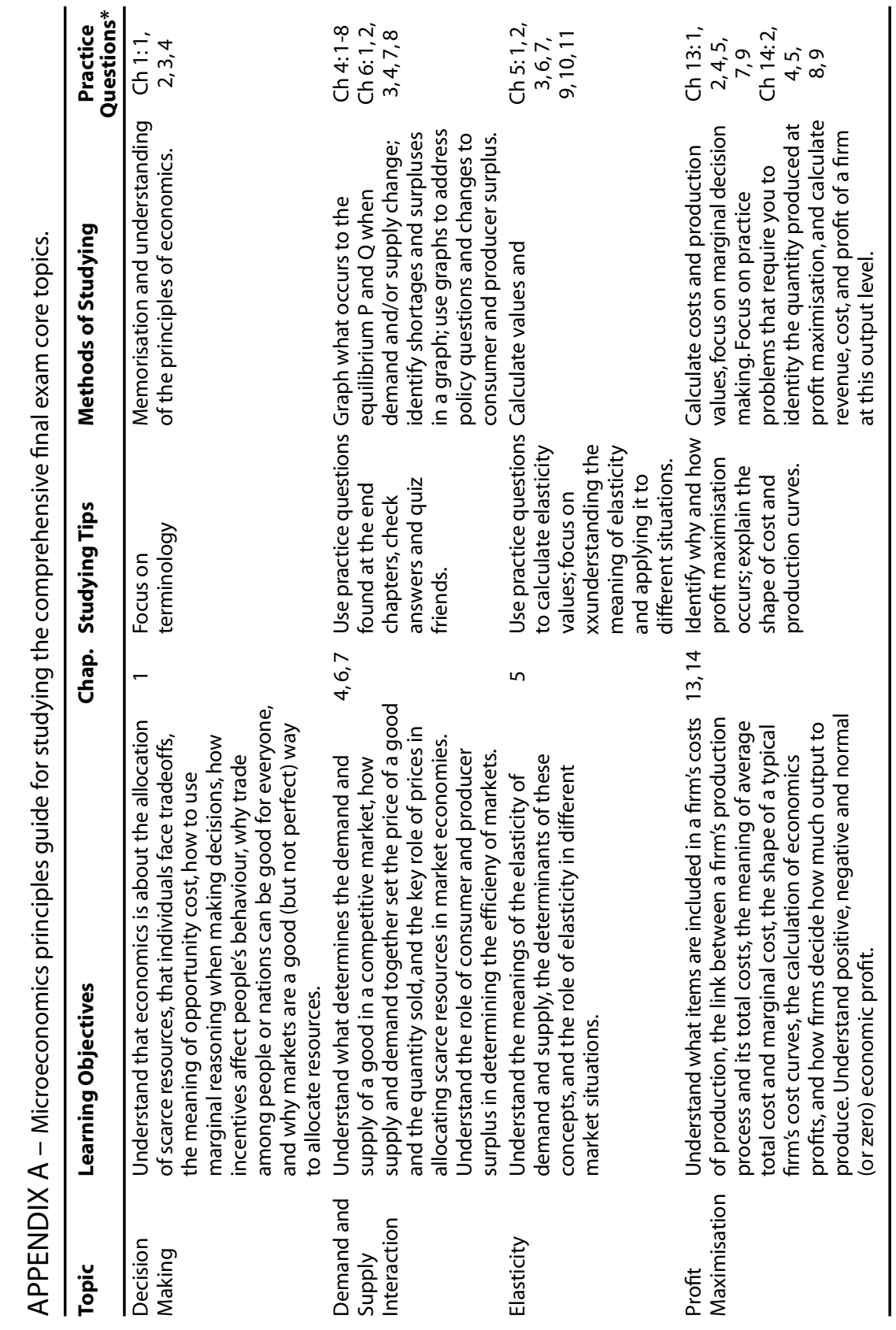




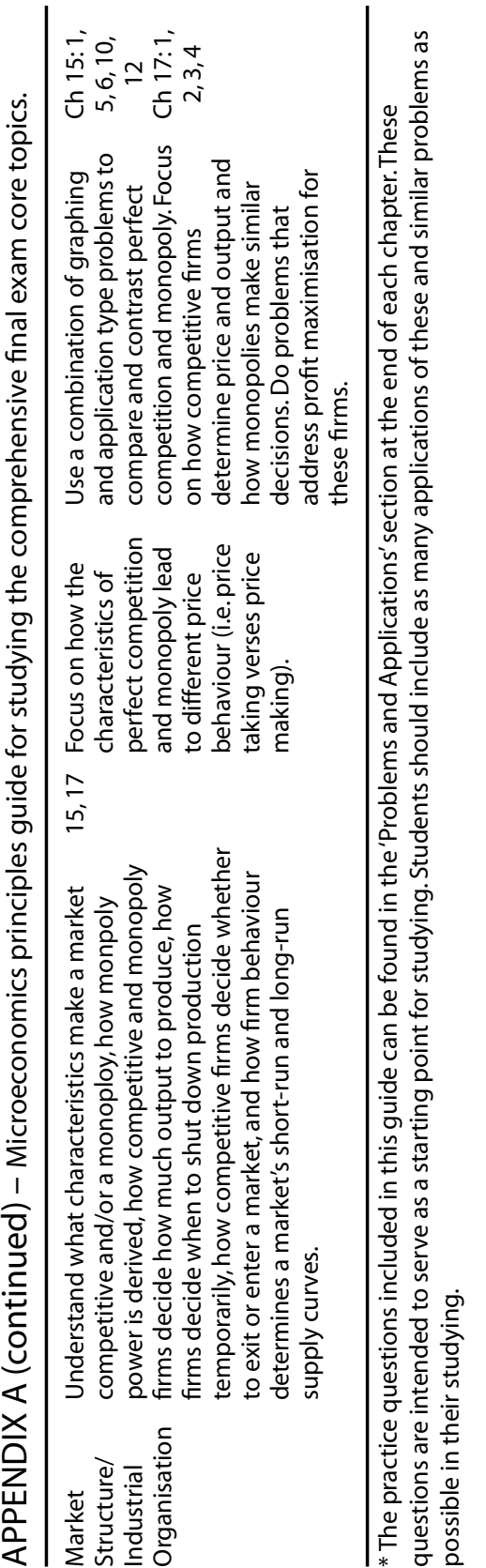

\section{Notes}

1 The university has a student population of approximately 7,500 students. The average SAT (Standardised Achievement Test used for U.S. college admissions with combined math and verbal score ranges from 400-1600) score for incoming freshman was 1104 in Fall 2006. A majority of students have Maryland residency (86\%), slightly more than a majority are women (57\%), while $17 \%$ are minority.

2 These questions along with the revised questions presented later in the text are available from the authors upon request.

3 The discrimination index used here measures the difference between the performance of the top $25 \%$ of the students and the bottom $25 \%$ of the students.

4429 students took the first version of the exam and 756 took the revised version but SAT scores were not reported for all students.

5 It is likely that even without intentional repetition of material by the instructor students recall and apply earlier material more often.

6 The inverse mills ratio is not significant in the estimation of exam scores that include student characteristics. This result suggests that any bias created by the exclusion of the students with missing SAT scores is corrected for with the inclusion of the transfer status dummy, thus leaving us to conclude that the OLS estimates are appropriate for policy review. A majority of the students that do not report the SAT score have transferred from other universities.

7 The verbal and mathematical SAT scores are found to be highly correlated so the scores are combined in this analysis.

\section{References}

Bloom, B. S. (1956) Taxonomy of educational objectives. Handbook I: Cognitive domain. New York, N.Y.: David McKay.

Bonesronning, H. (2003) 'Class Size Effect on Student Achievement in Norway: Patterns and Explanations', Southern Economic Journal 69: 952-965.

Finegan, T. Aldrich and John J. Siegfried (1999) 'Do Introductory Economics Students Learn More if Their Instructor Has a Ph.D.?', The American Economist 42 (2):34-46.

Fink, L. Dee (2003) Creating Significant Learning Experiences: An Integrated Approach to Designing College Courses. San Francisco: Jossey-Bass.

Grove, Wayne A.,Tim Wasserman and Andrew Grodner (2006) 'Choosing a Proxy for Academic Aptitude', Journal of Economic Education (Spring): 131-147.

Hansen, W. Lee (2001) 'Expected Proficiencies for Undergraduate Economics Majors', Journal of Economic Education (Summer): 231-242.

Johnston, Carol, lan McDonald and Ross Williams (2001) 'The Scholarship of Teaching Economics', Journal of Economic Education (Summer): 195-201.

Kennedy, Peter E. and John J. Siegfried (1997) 'Calls Size and Achievement in Introductory Economics Evidence from the TUCE II Data', Economics of Education Review, 16 (4):385-394.

McCoy, James P., Don Chamberlain and Rob Seay (1994)'The Status and Perceptions of University Outcomes Assessment in Economics', Journal of Economic Education (Fall): 358-366.

O'Neill, Patrick B. (2001) 'Essay Versus Multiple Choice Exams: An Experiment in the Principles of Macroeconomics Course', The American Economist, 45 (1):62-70. 
Raimondo, Henry J., Louis Esposito and Irving Gershenberg (1990) 'Introductory Class Size and Student Performance in Intermediate Theory Courses', Journal of Economic Education (Fall) 369-381.

Rothman, Mitchell P. and James H. Scott, Jr. (1973) 'Political Opinions and the TUCE' Journal of Economic Education (Spring): 116-123.

Saunders, Kent T. and Phillip Saunders (1999) 'The Influence of Instructor Gender on Learning and Instructor Ratings', Atlantic Economic Journal 27 (4): 460-473.

Saunders, Phillip and Arthur L. Welsh (1975) 'The Hybrid TUCE: Origin, Data and Limitations', Journal of Economic Education (Fall) 13-19.

Swartz, Thomas R., Frank J. Bonello, and William I. Davisson (1980) 'The Misuse of the TUCE in Explaining Cognitive Achievement', Journal of Economic Education (Winter) 23-33.

Walstad, William B. (2001) 'Improving Assessment in University Economics', Journal of Economic Education (Summer) 281-294.

Walstad, William B. (2005) 'Assessment of Student Learning in Economics', in Engaging Teaching Methods for Undergraduate Economics: More Alternative to Chalk and Talk,

William E. Becker and Michael Watts (Eds). Northampton MA: Edward Elgar.

Webber, Don J. (2005) 'Reflections on Curriculum Development, Pedagogy and Assessment by a New Academic', International Review of Economics Education 4 (1): 58-73.

\section{Acknowledgements}

We would like to thank Jim Hillman in the Information and Technology Department for help with the collection of student data available from university records. We would also like to thank the Salisbury University economics faculty for assistance with this project. We would like to particularly like to thank Silvana Chambers for providing invaluable support with both the administration of our assessment tools and for input with our teaching and learning approach changes.

\section{Contact details}

Jill Caviglia-Harris

Department of Economics and Finance

Salisbury University

1101 Camden Avenue

Salisbury, MD 21801

Email: jlcaviglia-harris@salisbury.edu

Brian Hill

Department of Economics and Finance

Salisbury University

1101 Camden Avenue

Salisbury, MD 21801

\section{An assessment of the impact of online quizzes and textbook resources on students' learning}

Monica Galizzi

\section{Introduction}

Despite the widespread diffusion of teaching technology in US colleges and universities (Goffe and Sosin, 2005), for a long time economics faculty were lagging behind instructors in other fields in adopting non-lecture teaching methods (Becker and Watts, 2001). Such hesitation could be partially explained by the fact that we still know relatively little about how different new instructional methods and software affect students' learning in economics classes (Katz and Becker, 1999). The available evidence is mainly based on students' learning outcomes in introductory classes, and it is quite mixed, depending on the technology that is assessed. For example, Agarwal and Day (1998) found that the use of the internet positively affected students' learning and attitudes toward economics and toward their instructor. Elliott (2003) and Lass et al., (2007) reported improvement in students' performance and in their enjoyment of lectures after introducing a Personal Response System. Brown and Liedholm (2002) found, however, that students' performance in virtual courses was inferior to that of students who took live or 'hybrid' classes where face-to-face lectures were integrated with a variety of online material.

Web-based homework is an additional teaching tool that is quickly spreading in response to the increasing teaching load faced by many instructors in universities that are operating under increasingly tight budgets. Textbook publishers have responded by offering additional online textbook resources, but we still know little about the effectiveness of these tools. Given the availability of personal computers and young students' familiarity with them, it is not surprising that students evaluate online homework positively (Dahlgarn, 2008; Smolira, 2008). The evidence on 